\title{
Tetramethylpyrazine inhibits migration of SKOV3 human ovarian carcinoma cells and decreases the expression of interleukin-8 via the ERK1/2, p38 and AP-1 signaling pathways
}

\author{
JUAN YIN ${ }^{1 *}$, CHAO YU $^{2 *}$, ZHU YANG $^{1}$, JUN-LIN HE ${ }^{2}$, WEN-JUAN CHEN ${ }^{1}$, \\ HAI-ZHONG LIU ${ }^{1}$, WEN-MING LI ${ }^{2}$, HONG-TAO LIU ${ }^{2}$ and YING-XIONG WANG ${ }^{2}$ \\ ${ }^{1}$ Department of Obstetrics and Gynecology, the Second Affiliated Hospital of Chongqing Medical University, \\ Chongqing 400010; ${ }^{2}$ Institute of Life Sciences, Chongqing Medical University, Chongqing 400016, P.R. China
}

Received March 14, 2011; Accepted April 21, 2011

DOI: 10.3892/or.2011.1334

\begin{abstract}
Interleukin-8 (IL-8) expression by melanoma cells may influence their metastatic capabilities. Tetramethylpyrazine (TMP) from Ligusticum wallichil Franch. possesses anti-inflammatory and antitumor activities. It has recently been suggested that autocrine IL-8 may play a role in tumor cell survival, invasion and migration. The role of TMP in association with IL- 8 in the tumor cell migratory process remains unclear. The purpose of the present study was to determine whether TMP influences the migratory ability of a human ovarian carcinoma cell line (SKOV3) via regulation of IL-8 expression in vitro. Cell counts showed that treatment of SKOV3 with TMP $(25-100 \mu \mathrm{g} / \mathrm{ml})$ for $24 \mathrm{~h}$ did not decrease cell numbers, while an effect of TMP on the down-regulation of the expression of IL-8 was observed. In addition, migration of SKOV3 cells was suppressed after treatment with TMP $(25-100 \mu \mathrm{g} / \mathrm{ml})$ for $24 \mathrm{~h}$. Therefore, expression of IL- 8 by SKOV3 cells correlates with their metastatic potential. Western blot analysis revealed that ERK1/2 and p38 phosphorylation was blocked by TMP. Furthermore, IL- 8 mRNA expression was inhibited significantly after co-incubation with PD98059 (ERK inhibitor) and SB203580 (p38 inhibitor), respectively. Notably, these changes were the results of activator protein-1
\end{abstract}

Correspondence to: Dr Zhu Yang, Department of Obstetrics and Gynecology, the Second Affiliated Hospital of Chongqing Medical University, Chongqing 400010, P.R. China

E-mail: cqyangz@vip.163.com

${ }^{*}$ Contributed equally

Abbreviations: TMP, tetramethylpyrazine; IL-8, interleukin-8; MAPK, mitogen-activated protein kinase; AP-1, activator protein-1

Key words: tetramethylpyrazine, interleukin-8, cell migration, mitogen-activated protein kinase, activator protein-1
(AP-1) activity suppression rather than that of NF- $\kappa$ B. Our data suggest that TMP may inhibit tumor cell invasion and migration, at least in part, through its down-regulation of IL-8 expression. Our results provide evidence that anti-inflammation plays an important role in integrative cancer therapies.

\section{Introduction}

The functional relationship between inflammation and cancer is widely accepted. Inflammation is a critical component of tumor progression, such as tumor cell metastasis (1). Metastasis, a complex and multiple process in which tumor cells spread from the primary site to distant organs, is one of the most common causes of morbidity and mortality in patients with ovarian carcinoma. The migratory capacity of cancer cells can be regulated by various factors including growth factors and cytokines (2), such as CXC-chemokine IL-8 (CXCL-8), a pro-inflammatory cytokine initially described as a neutrophil and monocyte chemoattactant, which modulates monocyte adhesion to endothelium and vascular smooth muscle cell migration (3-5). A direct correlation has also been demonstrated between overexpressed IL- 8 and the increased metastasis of tumor cells (6-8). Evidence has confirmed that tumor cells are able to respond to the autocrine release of IL-8, which enables tumor cells to have an additional growth and progression advantage (9). De Larco et al (10) reported that the concentration gradient of IL- 8 produced by tumor cells, which is higher at the primary tumor site than that at noncancerous sites, promotes distant metastasis of tumor cells. Moreover, IL-8 can recruit neutrophils to the primary tumor site through its chemoattractant capacity. In response to IL- 8 , the recruited neutrophils release proteases and heparanase which hydrolyze components of the extracellular matrix (ECM), subsequently destroying the normal tissue barrier and promoting tumor cell metastasis.

2,3,5,6-Tetramethylpyrazine (TMP) (molecular weight, 136.19), one of the major bioactive components purified from the Chinese herb Ligusticum wallichil Franch., has been widely used in treating cardiovascular and cerebral disease in 
China (11). In recent years, a number of other pharmacological effects of TMP have been identified. For instance, TMP was found to act as an anti-inflammatory agent in a rat asthma model (12). Previous data have demonstrated that TMP suppresses glioma cell line activity, including growth and migration, by inhibiting calcium influx (13). Similarly, Chen et al reported that TMP inhibits melanoma metastasis in vivo partly through suppressing VEGF activity (14). Therefore, TMP may be a potentially effective option for treatment of both inflammation and tumors. IL-8 production plays an important role in tumor metastasis, and TMP has been reported to inhibit melanoma metastasis activity. Whether TMP is associated with IL- 8 expression in the metastatic process remains unclear.

In the present study we evaluated the expression of IL-8 in human ovarian carcinoma cell line SKOV3 to determine whether IL-8 is associated with cell migration in vitro and to confirm whether TMP inhibits SKOV3 cell migration associated with IL-8 production. Our data indicated that TMP inhibits SKOV3 cell migration and decreases IL-8 production in vitro via ERK1/2, p38 and AP-1 signaling pathways.

\section{Materials and methods}

Chemicals and reagents. RIPA lysis buffer, acetoxymethyl ester (BCECF-AM), nuclear protein extraction kit, and BeyoECL Plus Western blotting detection reagent were obtained from Beyotime Institute of Biotechnology (Jiangsu, China). RPMI-1640, fetal bovine serum (FBS), antibiotics (penicillin/streptomycin), glutamine and collagenase were supplied by Gibco-BRL (Rockville, MD, USA). TRIzol was supplied by Sangon Biological Engineering Technology \& Services (Shanghai, China). Polymerase chain reaction (PCR) mixture was purchased from Takara Biotechnology (Liaoning, China). SB203580 and PD98059 were obtained from Calbiochem (San Diego, CA, USA). Anti-ERK1/2, antip-ERK1/2 and anti-activator protein 1 (AP-1) [p-c-Jun (ser 63/73)] antibodies were supplied by Santa Cruz Biotechnology (Santa Cruz, CA, USA). Anti-c-Jun antibody was purchased from Cell Signaling Technology (Beverly, MA, USA). AntiI $\kappa$ B $-\alpha$ antibody was obtained from Beyotime Institute of Biotechnology. Anti-p38 and anti-p-p38 were purchased from Cell Signaling Technology. Anti- $\beta$-actin antibody was obtained from Jiamei Biotech Technology (Hunan, China). Human IL-8 ELISA assay kits were purchased from Neobioscience Technology Company (Beijing, China). TMP was supplied by Sigma-Aldrich (St. Louis, MO, USA).

Cell culture and treatment. The human ovarian carcinoma cell line SKOV3 was kindly donated by Ultrasound Institute of Chongqing Medical University. SKOV3 cells were cultured in RPMI-1640 supplemented with $10 \%$ FBS. Cells were cultured in 100-mm dishes and grown in a humidified 5\% $\mathrm{CO}_{2}$ incubator. SKOV3 cells were plated at a density of $1 \times 10^{7}$ cells per $100-\mathrm{mm}$ dish. When cells reached subconfluence, they were pretreated for $24 \mathrm{~h}$ with culture medium containing different concentrations of TMP $(25,50$ and $100 \mu \mathrm{g} / \mathrm{ml})$ that were tested in the experiments.

U937 human monocytes were obtained from Shanghai Institute of Cell Biology (Shanghai, China) and grown in
RPMI-1640 supplemented with 10\% FBS, 2 mM L-glutamine, $25 \mathrm{mM}$ HEPES, $25 \mathrm{mM} \mathrm{NaHCO}$, $100 \mathrm{IU} / \mathrm{ml}$ penicillin and $10 \mu \mathrm{g} / \mathrm{ml}$ streptomycin.

Cell viability assay. SKOV3 cells were seeded at a density of $1 \times 10^{3}$ cells/well in 96-well plates. Cell viability was determined by methyl thiazoyl tetrazolium (MTT) assay (15). Briefly, at the indicated time after the treatment with or without TMP (25, 50, 100 and $400 \mu \mathrm{g} / \mathrm{ml})$, cells were washed with PBS and incubated with $100 \mu \mathrm{l}$ of MTT $(1 \mathrm{mg} / \mathrm{ml})$ in culture medium at $37^{\circ} \mathrm{C}$ for $4 \mathrm{~h}$. The culture medium with dye was then removed, and $100 \mu 1$ of dimethyl sulfoxide (DMSO) per well was added for formazan solubilization. The absorbance of the converted dye was measured at a wavelength of $490 \mathrm{~nm}$ using a Sunrise Remote Microplate Reader (Grodig, Austria). The viability of the SKOV3 cells in each well was expressed as a percentage versus the control (0.1\% DMSO medium) cells.

Wound healing assay. SKOV3 cells were seeded at a density of $7.5 \times 10^{4}$ cells per well in 24-well plates and were grown to $\sim 90 \%$ confluence after $36 \mathrm{~h}$. The medium was removed, and cell monolayers were wounded by manually scraping the cells with a $10-\mu 1$ plastic pipette tip. Debris was removed from the culture by washing with PBS twice, and cells were then cultured in RPMI-1640 containing 1\% FBS with TMP (25, 50 and $100 \mu \mathrm{g} / \mathrm{ml}$ ) for $24 \mathrm{~h}$. Images were captured $24 \mathrm{~h}$ post wounding with a Nikon TEU-2000 inverted microscope (magnification, x100). Wound sizes were verified using the scale of the images to ensure that all wounds had the same initial width.

Transwell assay. The lower chamber was filled with $0.6 \mathrm{ml}$ of RPMI-1640 medium containing $10 \%$ FBS as a chemoattractant. Following TMP treatment for $24 \mathrm{~h}$, cells were re-suspended in RPMI-1640 containing $1 \%$ FBS and added $\left(1 \times 10^{6}\right.$ cells $\left./ 100 \mu \mathrm{l}\right)$ to the upper chamber consisting of a polycarbonate membrane (8- $\mu \mathrm{m}$ pore size, Corning Life Science). After a 24-h incubation at $37^{\circ} \mathrm{C}$ under $5 \% \mathrm{CO}_{2}$, cells that had not migrated were removed, whereas migrated cells were fixed in 4\% PFA for $10 \mathrm{~min}$ at room temperature and stained with hematoxylin. The number of migrated cells were counted using an inverted microscope (Nikon TEU-2000). Experiments were performed in triplicate; a minimum of 10 grids (magnification, $\mathrm{x} 400$ ) per filter were counted.

Measurement of IL- 8 in the media. SKOV3 cells were seeded at a density of $1.5 \times 10^{5}$ cells/well in 24 -well plates and were grown to $\sim 70 \%$ confluence after $12 \mathrm{~h}$. The medium was removed, and cells were then cultured in RPMI-1640 containing $10 \%$ FBS with TMP $(25,50$ and $100 \mu \mathrm{g} / \mathrm{ml})$ for $24 \mathrm{~h}$. Supernatants were then collected and analyzed for IL-8 synthesis using enzyme-linked immunosorbent assay (ELISA) kits according to the manufacturer's protocol.

Preparation of RNA extraction and reverse transcriptionpolymerase chain reaction (RT-PCR). Total RNA was isolated from SKOV3 cells using TRIzol according to the manufacturer's instructions and quantified by UV absorbance at 260-280 nm. Reverse transcription was performed to produce cDNA. DNA samples were analyzed for specific cDNA of IL-8 and 

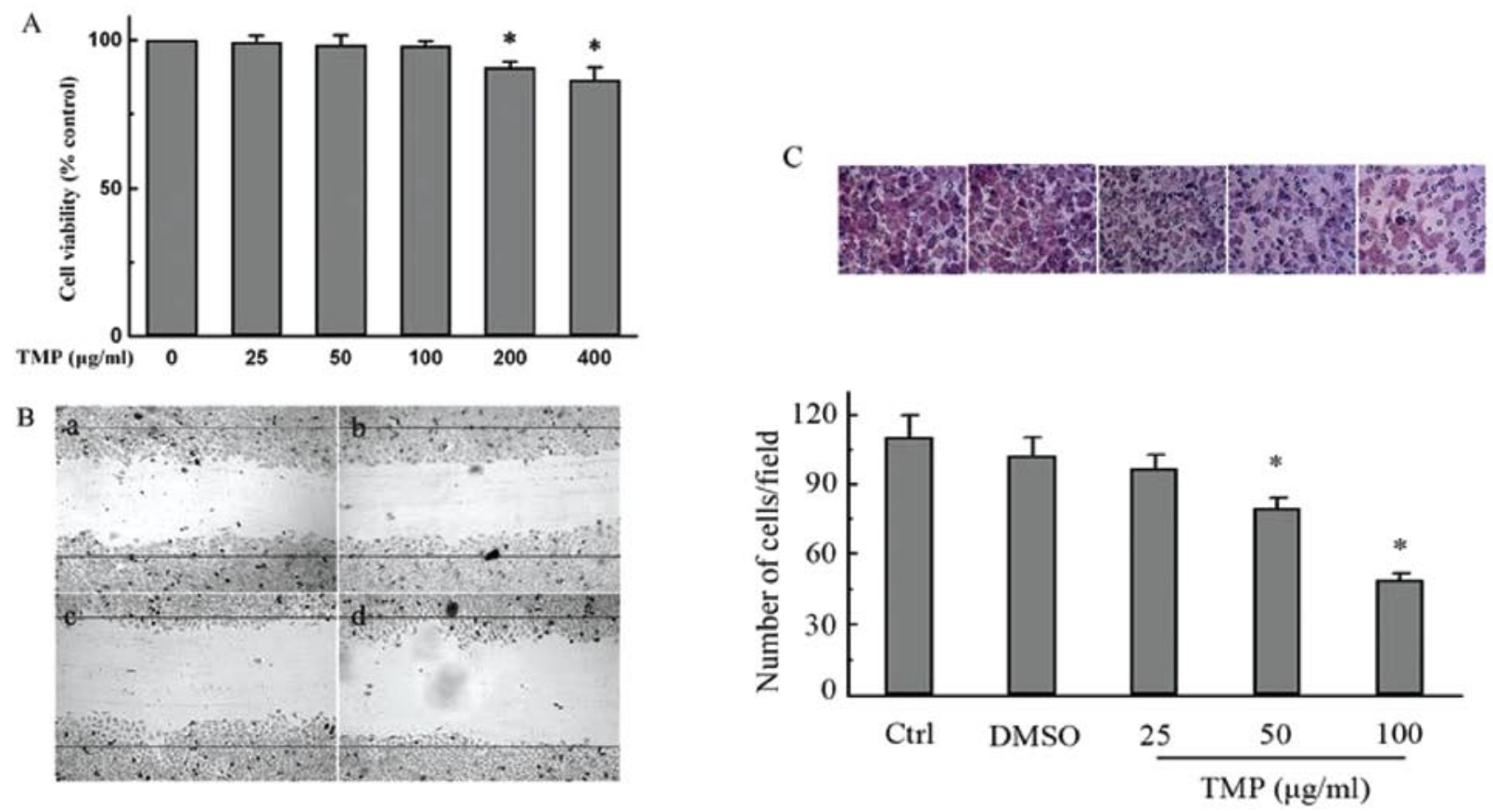

Figure 1. Effect of tetramethylpyrazine (TMP) on cell viability as determined by MTT assay in SKOV3 cells and the inhibitory effects of TMP on cell migration in vitro. (A) Cells were pretreated with $0.1 \%$ DMSO or various concentrations of TMP $(25,50,100,200$ and $400 \mu \mathrm{g} / \mathrm{ml})$ for $24 \mathrm{~h}$, and cell viability assays were performed using the MTT method as described in Materials and methods. (B) Confluent SKOV3 monolayers were wounded with a 10- $\mu 1$ pipette tip and treated with (a) $0.1 \%$ DMSO, (b) 25, (c) 50, and (d) $100 \mu \mathrm{g} / \mathrm{ml}$ TMP respectively for $24 \mathrm{~h}$. A representative image is shown (magnification, x100). Cell migration toward the center of the wounded area is noted. Black line indicates the wound edge. (C) Cells were seeded in the upper well of a Costar Transwell. After a $24 \mathrm{~h}$ incubation, the cells on the lower surface of the well were fixed and stained. The average number of migrated cells on the lower surface was quantified by counting under an inverted microscope. Values are means \pm SEM of three independent experiments. ${ }^{*}<<0.05$, compared to TMP-free Ctrl and DMSO groups.

glyceraldehyde-3-phosphate dehydrogenase (GAPDH) by PCR amplification using specific primers. The primers used for PCR were: IL-8, 5'-TCT CAG CCC TCT TCA AAA ACT TCT C-3' (forward) and 5'-ATG ACT TCC AAG CTG GCC GTG GCT-3' (reverse); GAPDH, 5'-CTC TCT GCT CCT CCT GTT CGA CAG-3' (forward) and 5'-GTG GAA TCA TAT TGG AAC ATG T-3' (reverse). cDNA $(5 \mu \mathrm{l})$ was added to $50 \mu \mathrm{l}$ of PCR mixture containing $33.5 \mu \mathrm{l}$ of $\mathrm{H}_{2} \mathrm{O}, 1 \mu \mathrm{l}$ of 5 ' primer (10 pM), $1 \mu 1$ of 3 ' primers, $4 \mu 1$ of dNTPs $(2.5 \mathrm{mM})$, $5 \mu 1$ of 10X PCR buffer, $0.5 \mu 1$ of Taq DNA polymerase ( $5 \mathrm{U} /$ $\mu 1)$. The following conditions were used for PCR amplification: 30 cycles of $30 \mathrm{sec}$ at $94^{\circ} \mathrm{C}, 30 \mathrm{sec}$ at $60^{\circ} \mathrm{C}$ and $1 \mathrm{~min}$ at $72^{\circ} \mathrm{C}$ for IL-8; 35 cycles for $30 \mathrm{sec}$ at $94^{\circ} \mathrm{C}, 30 \mathrm{sec}$ at $54^{\circ} \mathrm{C}$, and $1 \mathrm{~min}$ at $72^{\circ} \mathrm{C}$ for GAPDH. PCR products $(5 \mu \mathrm{l})$ were fractionated on $1.5 \%$ agarose gel containing $0.1 \mu \mathrm{g} / \mathrm{ml}$ dye (Gold View; SBS Genetech, Beijing, China). Gels were visualized and photographed by a Gel-Doc image analyzer (Bio-Rad, Hercules, CA, USA). The results were normalized against GAPDH, and presented as a target mRNA:GAPDH ratio.

Western blot analysis. SKOV3 cells were washed twice with ice-cold PBS and scraped in $1 \mathrm{ml}$ of the same buffer. After centrifugation at $10,000 \mathrm{xg}$, the cell pellet was suspended in ice-cold hypotonic lysis buffer (10 mM HEPES pH 7.9, $1.5 \mathrm{mM} \mathrm{MgCl} 2,0.2 \mathrm{mM} \mathrm{KCl}, 0.2 \mathrm{mM}$ phenylmethylsulphonylfluoride, $0.5 \mathrm{mM}$ dithiothreitol), vortexed for $2 \mathrm{~min}$ and then centrifuged at $12,000 \mathrm{x} \mathrm{g}$ for $15 \mathrm{~min}$. The supernatants were transferred to fresh tubes and assayed for protein content by the Bradford method (16). Protein samples $(100 \mu \mathrm{g})$ were electrophoretically fractionated with a discontinuous system consisting of $12 \%$ polyacrylamide resolving gels and $8 \%$ stacking gels, and then transferred to nitrocellulose membranes (Amersham, Buckinghamshire, UK) at $100 \mathrm{~V}$ and $250 \mathrm{~mA}$ (current constant) for $70 \mathrm{~min}$. The membranes were washed, blocked, and then incubated with primary antibodies. The bound horseradish peroxidase-conjugated secondary antibody was detected by an enhanced chemiluminescence procedure. Protein expression levels were determined by analyzing the signals captured on the nitrocellulose membranes using a Chemi-doc image analyzer (Bio-Rad).

Transient transfection and analysis of AP-1 reporter gene expression. SKOV3 cells (1.0x $10^{5}$ cells/well in 12 -well plates) were transfected with $0.5 \mu \mathrm{g}$ of pAP1-luc or expression vector (Beyotime Institute of Biotechnology) using SuperFect transfection reagent (Qiagen). Twenty-four hours after trans-fection, cells were treated with vehicle $(0.1 \%$ DMSO) or with various doses of TMP for $24 \mathrm{~h}$. Luciferase activities were measured with the Dual-Luciferase reporter assay system (Promega).

Adhesion of U937 mononuclear cells to SKOV3 monolayers. The cell adhesion assay was modified as described (17). U937 cells were labeled with BCECF-AM $(10 \mathrm{mg} / \mathrm{ml})$ for $60 \mathrm{~min}$ at $37^{\circ} \mathrm{C}$, washed, and re-suspended in serum-free media. SKOV3 cells were cultured and incubated with TMP $(25,50$ and $100 \mu \mathrm{g} / \mathrm{ml}$ ) for $24 \mathrm{~h}$ in a $24-w e l l$ culture plate, then co-cultured with BCECF-AM-labeled U937 cells for $30 \mathrm{~min}$ at $37^{\circ} \mathrm{C}$. Non-adhering U937 cells were removed by gentle aspiration, 
A
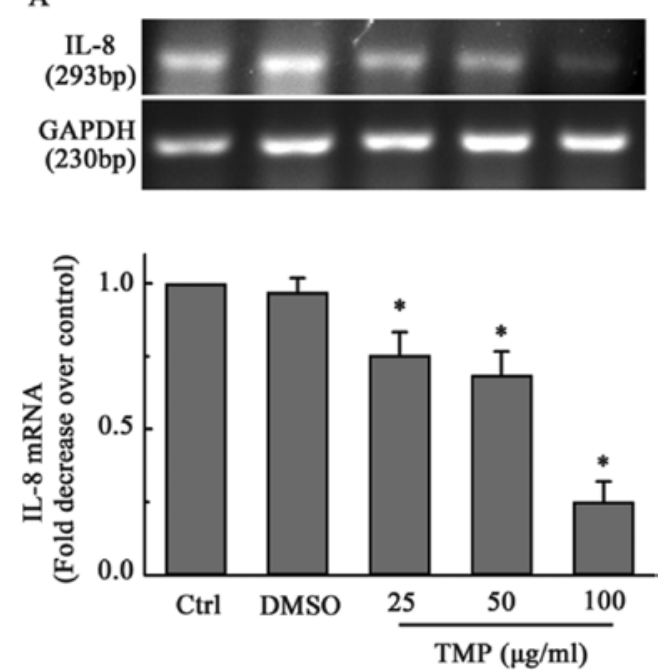

B

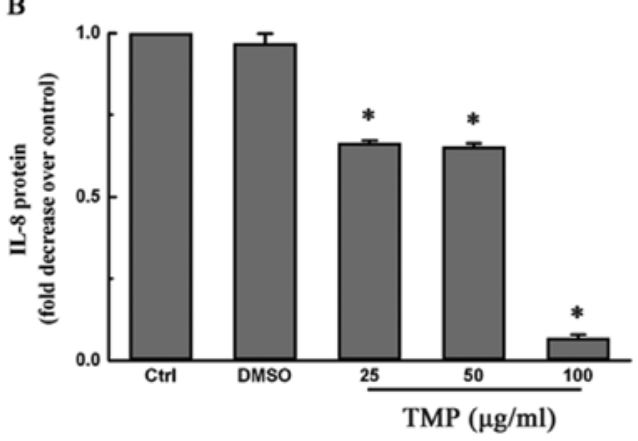

Figure 2. Tetramethylpyrazine (TMP) attenuates IL-8 production in SKOV3 cells. (A) Effect of TMP on IL-8 mRNA production. SKOV3 cells were cultured in medium in $50-\mathrm{cm}^{2}$ culture flasks with or without TMP (25$100 \mu \mathrm{g} / \mathrm{ml}$ ) for $24 \mathrm{~h}$. Total RNA was extracted and cDNA was synthesized from total RNA. Specific cDNA for IL-8 and GAPDH was amplified by reverse transcription-PCR. GAPDH was used as the control of the mRNA level. (B) Effect of TMP on IL-8 protein secretion. SKOV3 cells were cultured in medium in 24-well plates with or without various concentration of TMP $(25-100 \mu \mathrm{g} / \mathrm{ml})$ for $24 \mathrm{~h}$. The protein levels of IL-8 in the medium were measured by ELISA. The data are representative of three experiments (means $\pm \mathrm{SEM}$ ). ${ }^{*} \mathrm{p}<0.05$ compared to the TMP-free treated Ctrl and DMSO groups.

and wells were washed with PBS. The effect of TMP on U937 cell adhesion was assessed by pre-incubation with SKOV3 cells for $24 \mathrm{~h}$. U937 cells bound to SKOV3 cells were imaged with a Nikon TEU-2000 inverted microscope (magnification, $\mathrm{x} 100$ ), and data were analyzed using Image Pro Plus 6.0 software.

Statistical analysis. The results were expressed as mean \pm SEM of at least three independent experiments performed in triplicate. Treatment groups were compared using one-way analysis of variance (ANOVA) and the Newman-Keuls test was used to determine any significant differences identified in the ANOVA. $p<0.05$ was accepted as a significant difference.

\section{Results}

Cytotoxicity of TMP in SKOV3 cells and effect of TMP on cell migration. To determine the potential cytotoxicity of TMP, its inhibitory effect on the proliferation of SKOV3 cells was evaluated by MTT assay. Treatment with TMP did not inhibit cell proliferation at a low dose $(25-100 \mu \mathrm{g} / \mathrm{ml})$ for $24 \mathrm{~h}$, but exhibited limited cytotoxicity in SKOV3 cells at a dose up to $200 \mu \mathrm{g} / \mathrm{ml}$ compared with the untreated control groups. (Fig. 1A). Thus, concentrations of $25-100 \mu \mathrm{g} / \mathrm{ml}$ of TMP were adopted in the subsequent experiment.

The migration of cells is a crucial step in the malignization of carcinoma. Thus, we first examined the effect of TMP on the migration of SKOV3 cells in vitro. Cells were seeded in 24-well plates, and a wound healing assay was performed. As shown in Fig. 1B, a large number of SKOV3 cells migrated toward the center of the wound area in the absence of TMP (a). Treatment with $25 \mu \mathrm{g} / \mathrm{ml}$ TMP resulted in reduced migration toward the center of the wound (b). The number of cells that migrated to the center of wound was further decreased after treatment with TMP for $24 \mathrm{~h}$ at higher concentrations (50 and $100 \mu \mathrm{g} / \mathrm{ml}, \mathrm{c}$ and d, respectively). Similar results were obtained in a Transwell assay. As shown in Fig. 1C, treatment of SKOV3 cells with a higher concentration $(100 \mu \mathrm{g} / \mathrm{ml})$ of TMP significantly decreased cell migration ( 2-fold) compared with vehicle treatment. These results suggest that TMP suppresses SKOV3 cell migration dose-dependently in vitro.

Effect of TMP on IL-8 production in SKOV3 cells. To confirm whether the anti-migratory effect on SKOV3 cells is associated with IL- 8 production, the expression of IL- 8 in the SKOV3 treated with TMP was determined. Cells were incubated with various concentrations of TMP $(25,50$ and $100 \mu \mathrm{g} / \mathrm{ml})$ for $24 \mathrm{~h}$, and the mRNA level of IL- 8 was found to be reduced by 1.3- to 4.0-fold $(\mathrm{p}<0.05)$ as the concentration of TMP increased (Fig. 2A). The secretion of IL-8 into the culture medium was also significantly reduced by TMP pretreatment in a dosedependent manner (Fig. 2B). Therefore, the inhibition of SKOV3 migration by TMP may be associated with attenuation of IL-8 production.

Effect of TMP on U937 cell adhesion in SKOV3 cells. IL-8 was found to stimulate monocyte adhesion to endotheliocytes in inflammation (5). We hypothesied that IL-8 stimulates monocyte adhesion to ovarian tumor SKOV3 cells. Thus, we tested whether TMP can block this effect. The adhesion of U937 monocytes to SKOV3 cells treated with various doses of TMP for $24 \mathrm{~h}$ was assessed. TMP was found to significantly attenuate the adherent ability of monocytes to SKOV3 cells $(\mathrm{p}<0.05)$ in a dose-dependent manner (Fig. 3). When SKOV3 cells were pretreated with $100 \mu \mathrm{g} / \mathrm{ml} \mathrm{TMP}$, the adherent rate of U937 monocytes to SKOV3 decreased by $34 \%$ versus the control groups. The result indicates that TMP inhibits the adherence of monocytes to SKOV3 cells induced by IL-8 production.

TMP inhibits IL-8 production through mitogen-activated protein kinase (MAPK) signaling pathways. It has been wellestablished that MAPK signaling pathways play a crucial role in cancer cell migration (18). We further investigated whether MAPK pathways are related to the down-regulation of IL-8 by TMP in SKOV3 cells. After exposure to TMP (25, 50 and $100 \mu \mathrm{g} / \mathrm{ml}$ ) for $24 \mathrm{~h}$, cells were harvested and proteins were examined by Western blotting. Quantitative analysis of ERK1/2 (Fig. 4A) or p38 (B) band by densitometry revealed a 

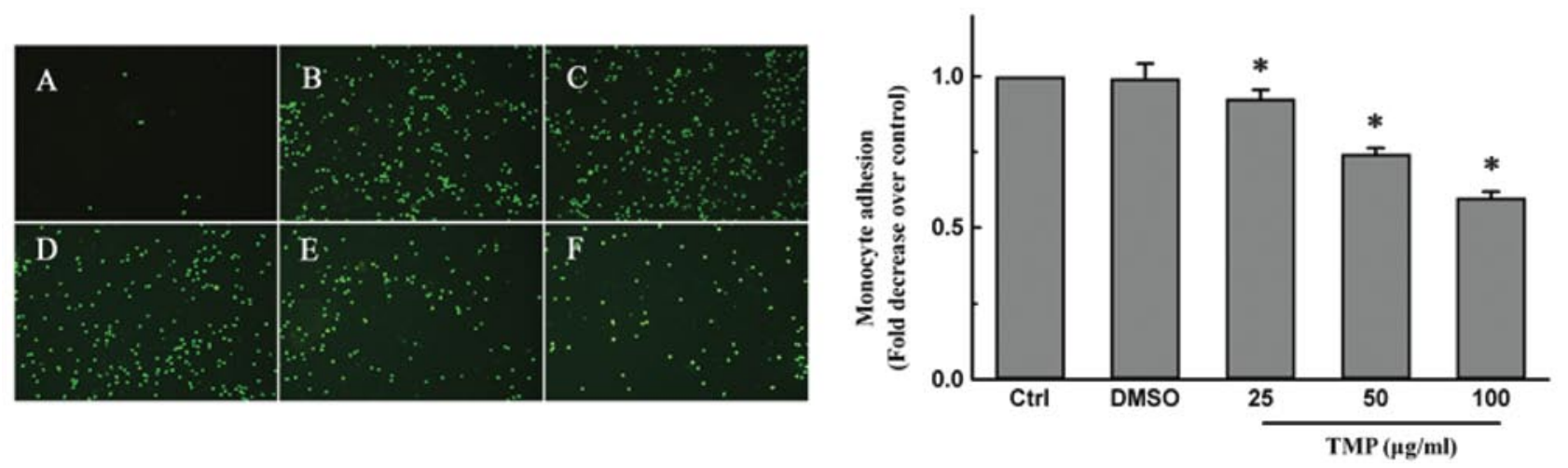

Figure 3. Inhibition by tetramethylpyrazine (TMP) of the binding of U937 monocytes to SKOV3 cells. SKOV3 cells were pretreated without TMP [(A) blank and (B) control, (C) $0.1 \%$ DMSOl or with (D) 25, (E) 50, (F) $100 \mu \mathrm{g} / \mathrm{ml}$ TMP for $24 \mathrm{~h}$. After co-incubation of fluorescent-labeled U937 monocytes with SKOV3 cells for $30 \mathrm{~min}$ at $37^{\circ} \mathrm{C}$, monocyte adhesion was presented as a percentage of U937 cells bound to SKOV3 cells (histograph). Data represent mean \pm SEM of three separate experiments. " $\mathrm{p}<0.05$, compared to the control group.

significant $(\mathrm{p}<0.05)$ decrease in phosphorylation levels in TMP-treated groups compared with control groups.

To confirm the role of the MAPK pathways in the downregulation of IL-8 by TMP, the effect of PD98059 (30 $\mu \mathrm{M})$, a specific ERK inhibitor, and SB203580 $(25 \mu \mathrm{M})$, a specific p38 inhibitor, on IL-8 mRNA expression was investigated. As shown in Fig. 4C and D, both inhibitors significantly suppressed IL-8 production $(\mathrm{p}<0.05)$ in vitro. These results confirmed that down-regulation of IL-8 in SKOV3 cells by TMP was a direct consequence of the suppression of the phosphorylation level of ERK and $\mathrm{p} 38$.

Since NF- $\mathrm{BB}$ is downstream of MAPK (19), we determined the effect of TMP on NF- $\mathrm{kB}$ activation in SKOV3 cells. Total I $\kappa \mathrm{B}-\alpha$, the natural inhibitor of NF- $\kappa \mathrm{B}$, was assessed by Western blotting following the pretreatment of SKOV3 cells with TMP at concentrations of 25,50 and $100 \mu \mathrm{g} / \mathrm{ml}$ for $24 \mathrm{~h}$. As shown in Fig. 4E, TMP did not alter the expression of IкB- $\alpha$. Moreover, IкB- $\alpha$ expression was not altered by treatment of TMP at $100 \mu \mathrm{g} / \mathrm{ml}$ from 0.5 to $24 \mathrm{~h}$ (Fig. 4F). Together, these findings suggest that suppression of ERK and p38 by TMP depends on the inhibitive activity of other nuclear factors, other than NF- $\mathrm{kB}$.

Effect of TMP on activator protein 1 activation. As the IL-8 promoter region -133 to -70 contains binding sites, not only for NF- $\kappa \mathrm{B}$, but also for AP-1; we evaluated the effect of TMP on AP-1 activation in SKOV3 cells. Firstly, activation of the AP-1 promoter was investigated in a luciferase reporter gene assay in SKOV3 cells followed by TMP treatment. As shown in Fig. 5A, AP-1 reporter activation was significantly attenuated by TMP (50-100 $\mu \mathrm{g} / \mathrm{ml})$. Previous studies have shown that AP-1 binding activity is dependent on the phosphorylation of c-Jun (20). Thus, we further investigated the role of c-Jun in the down-regulation of IL- 8 production by TMP. As shown in Fig. 5B, phosphorylation levels of c-Jun in nuclear extracts were decreased significantly in SKOV3 cells after exposure to TMP at $100 \mu \mathrm{g} / \mathrm{ml}$ compared with the control groups. These results indicate that TMP decreases IL-8 expression partly through suppressing the activation of AP-1.

Effect of ERK and p38 inhibitors on cell migration. To gain insight into the effect of IL-8 down-regulation by MAPK inhibitors on cell motility, a wound healing assay was carried out. A subconfluent cell monolayer was scratched, and cells were allowed to migrate into the cell-free area. The distance moved by the MAPK inhibitor-treated cells was much smaller than that of the control (0.01\% DMSO) cells at $24 \mathrm{~h}$ (Fig. 6C and D), the same as noted for TMP (Fig. 6B). Collectively, these data demonstrated that TMP down-regulation of IL-8 by the MAPK pathway could, at least in part, lead to the inhibition of migration of SKOV3 cells.

\section{Discussion}

IL-8 overexpression has been reported in various types of malignancies and is frequently associated with poor clinical outcome and decreased patient survival (21). Blockade of IL-8 activity with a monoclonal antibody has been shown to decrease tumor growth in two murine cancer models $(22,23)$. Moreover, Merritt et al (24) used systemic siRNA delivery to silence IL-8 expression in an orthotopic murine model of ovarian carcinoma, leading to a statistically significant reduction in orthotopic tumor growth and spread, suggesting that IL-8 may be a potential therapeutic target in ovarian cancer. However, few studies have investigated the targeting of IL-8 as a therapeutic strategy in ovarian cancer. The mechanism of how chemotherapy effectively reduces IL-8 expression in ovarian cancer remains poorly understood.

TMP has been previously described in the literature as an antioxidant and anti-inflammatory agent, capable of inhibiting cell migration and proliferation in glioma cells (13) and melanoma metastasis (14). Our previous data demonstrated that TMP suppresses IL-8 production in lipopolysaccharidestimulated human umbilical vein endothelial cells (25). To provide a direct evidence for the contribution of TMP on decreased IL- 8 production and its association with cell migration of ovarian cancer, we decided to treat SKOV3 cells with TMP and subsequently analyze the changes in IL-8 expression and cell migration potential. The data confirmed that TMP exerts anti-migratory activity at a lower concentration (25-100 $\mu \mathrm{g} / \mathrm{ml}$ ) through down-regulation of IL-8 production in human ovarian tumor SKOV3 cells. Our results are similar to those reported by Inoue et al (26), who found that reduced IL-8 expression in the highly tumorigenic and metastatic PC-3M-LN4 
A
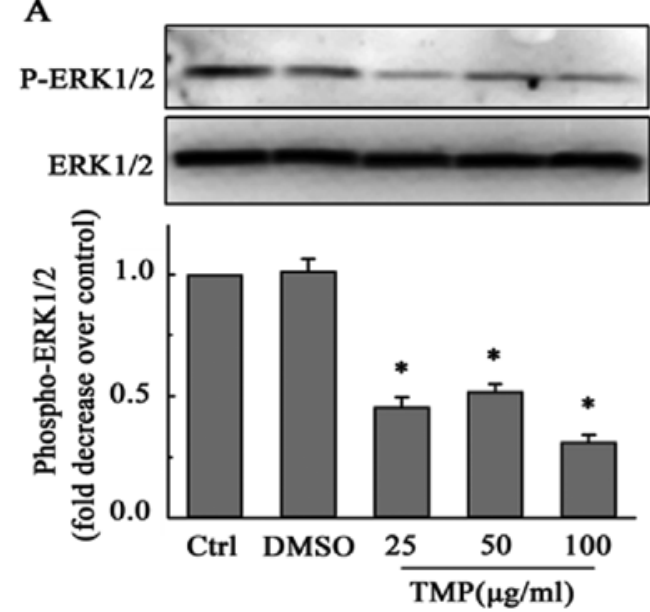

C
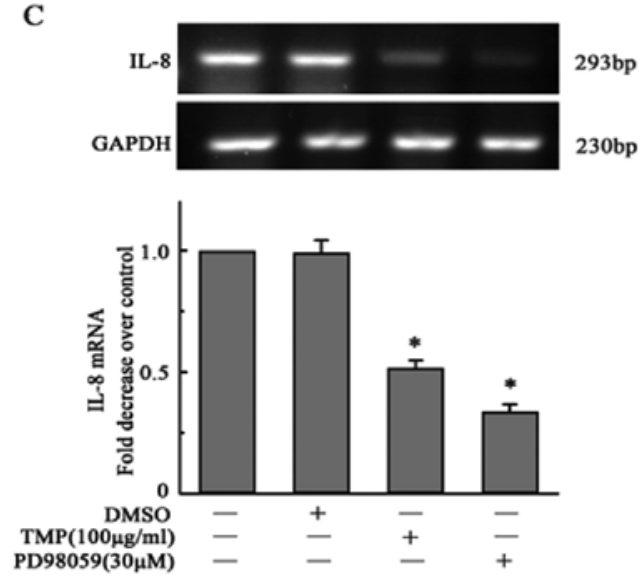

E

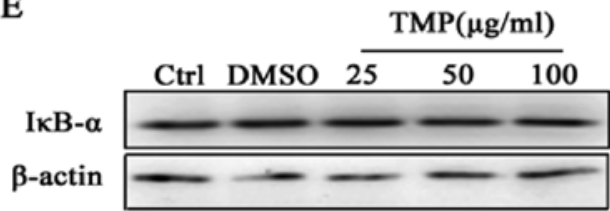

B

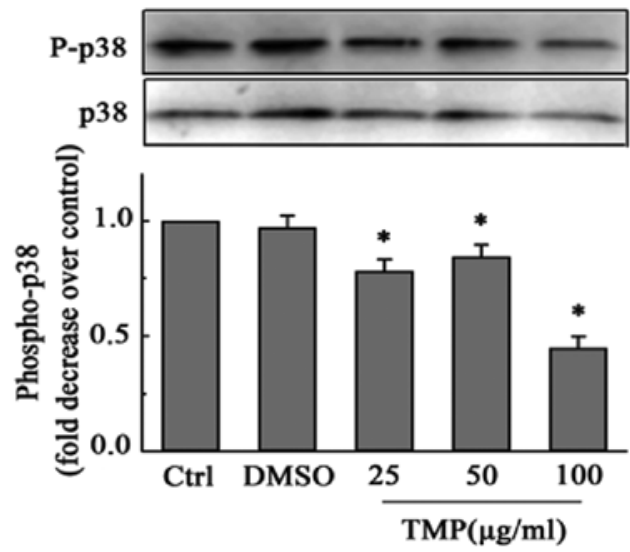

D

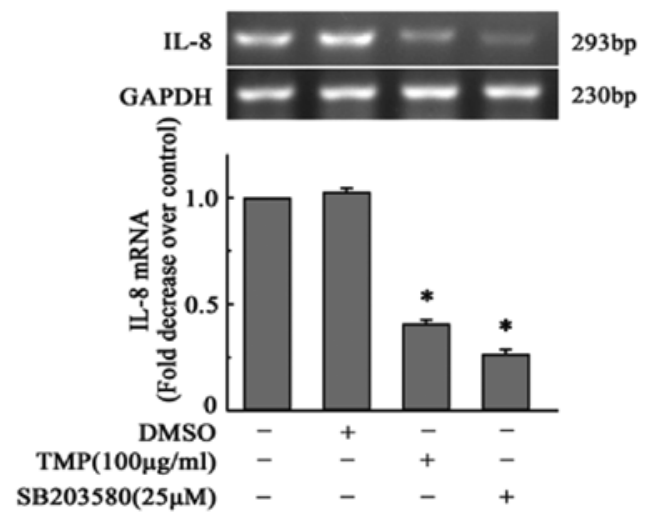

F

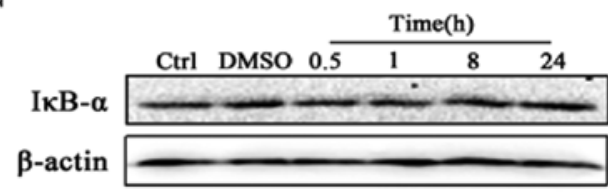

Figure 4. Effect of tetramethylpyrazine (TMP) on mitogen-activated protein kinase (MAPK) phosphorylation and NF-kB activation in SKOV3 cells. SKOV3 cells were cultured in 50- $\mathrm{cm}^{2}$ flasks without or with various concentrations of TMP $(25-100 \mu \mathrm{g} / \mathrm{ml})$ for $24 \mathrm{~h}$. The phosphorylation of ERK1/2 and p38 was analyzed by Western blot analysis. The intensity of the band for P-ERK1/2 (A), P-p38 MAPK (B) was expressed as a ratio to total ERK and p38 MAPK, respectively. SKOV3 cells were treated for $24 \mathrm{~h}$ with PD98059 (30 $\mu \mathrm{M})(\mathrm{C})$, or SB203580 (25 $\mu \mathrm{M})(\mathrm{D})$, respectively. Total mRNA was subjected to RT-PCR to analyze the change in IL-8 expression. GAPDH served as a loading control. Quantitative analyses are shown below the gel data. SKOV3 cells were treated with TMP $(25-100 \mu \mathrm{g} / \mathrm{ml})$ for $24 \mathrm{~h}$. Equal amounts of protein extracts from tumor cells were subjected to Western blot analysis with antibodies against IkB- $\alpha$ and $\beta$-actin (E). SKOV3 cells were exposed to TMP at $100 \mu \mathrm{g} / \mathrm{ml}$ for various time periods, and cell lysates were subjected to Western blot analysis with IкB- $\alpha$ and $\beta$-actin antibodies $(F)$. Data are shown as the mean of three independent experiments with triplicate samples and are expressed as the mean \pm SD. $* \mathrm{p}<0.05$ compared with control.

cell line via antisense IL-8 transfection inhibited tumor growth in the prostate and metastasis. Thus, down-regulation of IL-8 by TMP in SKOV3 cells should have a beneficial effect by decreasing cell migration.

The intracellular signal transduction pathways inducing autocrine IL-8 in ovarian carcinoma is complex. Proinflammatory cytokines, such as TNF $\alpha$ and IL-1 $\beta$, as well as LPS are known to induce IL- 8 expression via NF- $\kappa B$ containing transcription factor complexes targeting the IL-8 promoter (27-29). Both ERK1/2 and p38 MAPK signaling pathways are associated with tumor cell migration (18). In various cell types and conditions, the regulation of IL-8
mRNA stability is a well-accepted and important mechanism of IL- 8 mRNA expression $(25,30)$. Accumulating evidence has revealed that the $\mathrm{p} 38$ MAPK signaling pathway, and to a minor extent ERK1/2, controls IL-8 mRNA stability (31-33). In the present study, we also demonstrated that inhibition of the phosphorylation of $\mathrm{p} 38$ and ERK1/2 by TMP and inhibitor resulted in a decrease in the IL- 8 mRNA level and therefore IL-8 production that can be partially abolished by inhibiting the MAPK signaling pathway. A comparable mechanism was previously described for TMP. Lee et al (34) reported that TMP significantly decreased Ang II-induced ERK1/2 phosphorylation in vascular endothelial cells. Moreover, TMP 
A
B
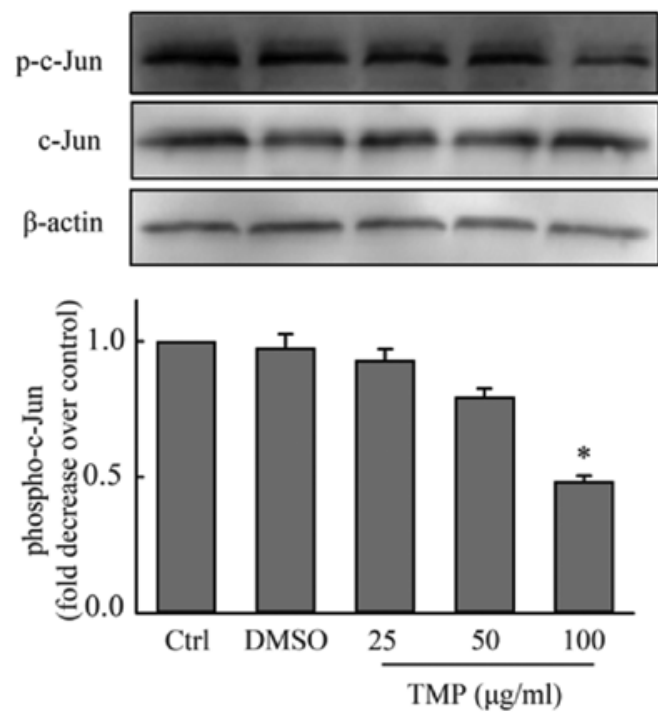

Figure 5. Effect of tetramethylpyrazine (TMP) on activator protein 1 (AP-1) activation in SKOV3 cells. SKOV3 cells were transfected with pAP1-luc, and incubated with TMP $(25-100 \mu \mathrm{g} / \mathrm{ml})$ for $24 \mathrm{~h}$. The luciferase reporter construct possessed consensus activator protein-1 binding sites (A). Cells were treated with TMP (25-100 $\mu \mathrm{g} / \mathrm{ml})$ for $24 \mathrm{~h}$. Proteins were extracted and subjected to Western blot analysis. The expression of phospho-c-Jun was compared with that of c-Jun to control for protein loading (B). The results are representative of three independent experiments. *p $<0.05$ compared with the control.
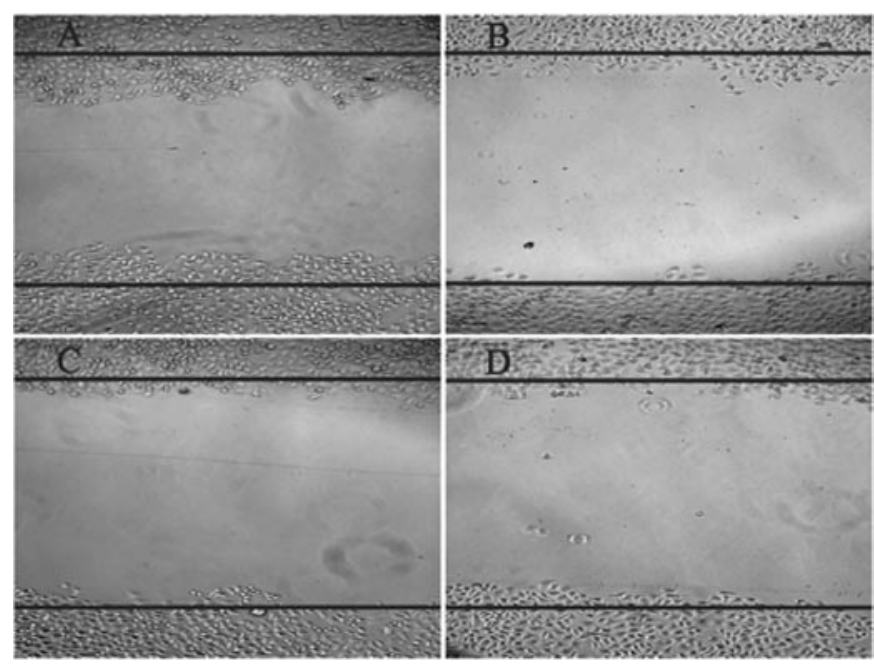

Figure 6. Effect of ERK and $\mathrm{p} 38$ inhibitors on the migration of SKOV3 cells. Confluent SKOV3 monolayers were wounded and treated with (A) $0.1 \%$ DMSO, (B) TMP (100 $\mu \mathrm{g} / \mathrm{ml})$, (C) PD98059 $(30 \mu \mathrm{M})$, and (D) SB203580 $(25 \mu \mathrm{M})$ for $24 \mathrm{~h}$. A representative diverse phase contrast image is shown (magnification, x100).

inhibited LPS-induced nitric oxide (NO) through the blocking of the phosphorylation of p38 MAPK, ERK1/2 in N9 cells (35). In addition, the effect of TMP on attenuating LPSinduced IL- 8 production, was found to be related to suppression of ERK1/2 and p38 MAPK activity in human umbilical vein endothelial cells (25). Herein, we suggested that one mechanism involved in the attenuation of IL- 8 expression by TMP is the modulation of IL-8 mRNA stability through a decrease in the phosphorylation levels of ERK1/2 and p38 in SKOV3 cells.

Considering the cellular target sites for regulating IL-8 expression and subsequent secretion, there are several possible sites, such as NF- $\kappa \mathrm{B}$ and AP-1. A previous report demonstrated that constitutive expression of IL-8 was controlled via NF- $\mathrm{B}$, which could regulate transcription of target genes in bladder tumors (36). In ovarian tumor cells, hypoxia-mediated transient induction of IL-8 expression required the cooperation of AP-1 and NF- $\mathrm{B}$ binding elements (37). Meanwhile, in an acidic ovarian tumor environment, AP-1 and NF- $\kappa \mathrm{B}$ binding sites were indispensable to IL-8 expression in SKOV3 cells (38). Thus, constitutive expression of IL- 8 may be controlled via NF- $\kappa \mathrm{B}$ and/or AP-1 in SKOV3 cells. Based on these findings, we first hypothesized that one potential mechanism of the suppression of IL- 8 expression by TMP underlies the blockade of $\mathrm{NF}-\kappa \mathrm{B}$ activation. Unfortunately, we failed to observe any change in I $\kappa \mathrm{B}-\alpha$, the natural inhibitor of $\mathrm{NF}-\kappa \mathrm{B}$, after TMP treatment in SKOV3 cells. Then, further investigation was performed to discover whether AP-1, another IL-8-production-dependent transcriptional factor, was altered by TMP during the anti-migratory effect in SKOV3 cells. In the present study, we found that TMP inhibited AP-1 transcriptional activation through a luciferase assay. Results were in accordance with the findings that TMP inhibited endothelin-1-induced AP-1 activity in endothelial cells (39). Since AP-1 is a compound protein which mainly consists of c-Jun and Fos heterodimers (40), we detected the effect of TMP on the activation of c-Jun. We observed a marked decrease in the phosphorylated c-Jun level in the SKOV3 cells treated with TMP for $24 \mathrm{~h}$. Therefore, we confirmed that TMP inhibited IL-8 expression through a decrease in AP-1 activation. These results highlight the growing importance and the increased focus of employing TMP for clinical use.

Limitations of this study included those related to the use of cell lines as a model of human malignancies and unclear downstream IL-8 activation. For example, cell lines may not reflect the heterogeneity present in human tumors. Moreover, it has been considered that the up-regulation of collagenase activity by IL- 8 is an important mechanism to explain the associated increase in metastatic ability. Luca et al (7) reported that IL- 8 induces MMP-2 activity in malignant 
melanoma cells. Similarly, Inoue et al (41) found that the activity of MMP-9 in TCC cells is directly correlated with the expression of IL-8. Whether the anti-migratory effect of TMP by inhibition of IL-8 production is mediated, in part, by the expression and activity of MMP-9 or MMP-2 in SKOV3 cells warrants further investigation in the future.

In summary, our present study demonstrates that TMP inhibited cell migration induced by autocrine IL-8 production in SKOV3 cells, suggesting that the anti-migratory effect of TMP appears to be an important mechanism for its clinical prevention of ovarian carcinoma. Our findings support the notion that anti-inflammatory action plays an important role in anti-cancer therapy. This study also sheds light on the mechanism of IL-8 in promoting ovarian cancer cell migration.

\section{Acknowledgements}

We are grateful for the financial support from the National Nature Science Foundation of China (Project No. 30973169) and Nature Science Foundation of Chongqing (Project No. CSTC, 2009BA5083). We also appreciate Professor Xiao-qiu Xiao for the critical reading and editorial assistance.

\section{References}

1. Coussens LM and Werb Z: Inflammation and cancer. Nature 420: 860-867, 2002.

2. Kim SW, Hayashi M, Lo JF, et al: Tid1 negatively regulates the migratory potential of cancer cells by inhibiting the production of interleukin-8. Cancer Res 65: 8784-8791, 2005.

3. Baggiolini M, Dewald B and Moser B: Human chemokines: an update. Annu Rev Immunol 15: 675-705, 1997.

4. Matsushima K and Oppenheim JJ: Interleukin 8 and MCAF: novel inflammatory cytokines inducible by IL-1 and TNF. Cytokine 1: 2-13, 1989.

5. Gerszten RE, Garcia-Zepeda EA, Lim YC, et al: MCP-1 and IL-8 trigger firm adhesion of monocytes to vascular endothelium under flow conditions. Nature 398: 718-723, 1999.

6. Singh RK, Gutman M, Radinsky R, Bucana CD and Fidler IJ: Expression of interleukin 8 correlates with the metastatic potential of human melanoma cells in nude mice. Cancer Res 54 3242-3247, 1994

7. Luca M, Huang S, Gershenwald JE, Singh RK, Reich R and Bar-Eli M: Expression of interleukin- 8 by human melanoma cells up-regulates MMP-2 activity and increases tumor growth and metastasis. Am J Pathol 151: 1105-1113, 1997.

8. De Larco JE, Wuertz BR, Rosner KA, et al: A potential role for interleukin-8 in the metastatic phenotype of breast carcinoma cells. Am J Pathol 158: 639-646, 2001.

9. Brew R, Erikson JS, West DC, Kinsella AR, Slavin J and Christmas SE: Interleukin-8 as an autocrine growth factor for human colon carcinoma cells in vitro. Cytokine 12: 78-85, 2000.

10 De Larco JE, Wuertz BR and Furcht LT: The potential role of neutrophils in promoting the metastatic phenotype of tumors releasing interleukin-8. Clin Cancer Res 10: 4895-4900, 2004

11. Li WM, Liu HT, Li XY, et al: The effect of tetramethylpyrazine on hydrogen peroxide-induced oxidative damage in human umbilical vein endothelial cells. Basic Clin Pharmacol Toxicol 106: 45-52, 2009.

12 Xiong L, Fang ZY, Tao XN, Bai M and Feng G: Effect and mechanism of ligustrazine on Th1/Th2 cytokines in a rat asthma model. Am J Chin Med 35: 1011-1020, 2007.

13. Fu YS, Lin YY, Chou SC, et al: Tetramethylpyrazine inhibits activities of glioma cells and glutamate neuro-excitotoxicity: potential therapeutic application for treatment of gliomas. Neuro Oncol 10: 139-152, 2008.

14. Chen L, Lu Y, Wu JM, et al: Ligustrazine inhibits B16F10 melanoma metastasis and suppresses angiogenesis induced by vascular endothelial growth factor. Biochem Biophys Res Commun 386: 374-379, 2009.
15. Mosmann T: Rapid colorimetric assay for cellular growth and survival: application to proliferation and cytotoxicity assays. $\mathrm{J}$ Immunol Methods 65: 55-63, 1983.

16. Bradford MM: A rapid and sensitive method for the quantitation of microgram quantities of protein utilizing the principle of protein-dye binding. Anal Biochem 72: 248-254, 1976.

17. Yang YY, Hu CJ, Chang SM, Tai TY and Leu SJ: Aspirin inhibits monocyte chemoattractant protein-1 and interleukin- 8 expression in TNF- $\alpha$ stimulated human umbilical vein endothelial cells. Atherosclerosis 174: 207-213, 2004.

18. Estrada Y, Dong J and Ossowski L: Positive crosstalk between ERK and p38 in melanoma stimulates migration and in vivo proliferation. Pigment Cell Melonoma Res 22: 66-76, 2009.

19. MahéY, Mukaida N, Kuno K, et al: Hepatitis B virus X protein transactivates human interleukin-8 gene through acting on nuclear factor $\kappa \mathrm{B}$ and CCAAT/enhancer-binding protein-like cis-elements. J Bio Chem 266: 13759-13763, 1991.

20. Roebuck KA: Regulation of interleukin-8 gene expression. J Interferon Cytokine Res 19: 429-438, 1999.

21. Xie K: Interleukin-8 and human cancer biology. Cytokine Growth Factor Rev 12: 375-391, 2001.

22. Mian BM, Dinney CP, Bermejo CE, et al: Fully human antiinterleukin 8 antibody inhibits tumor growth in orthotopic bladder cancer xenografts via down-regulation of matrix metalloproteases and nuclear factor-kappaB. Clin Cancer Res 9: 3167-3175, 2003.

23. Huang S, Mills L, Mian B, et al: Fully humanized neutralizing antibodies to interleukin-8 (ABX-IL8) inhibit angiogenesis, tumor growth, and metastasis of human melanoma. Am J Pathol 161: 125-134, 2002.

24. Merritt WM, Lin YG, Spannuth WA, et al: Effect of interleukin-8 gene silencing with liposome-encapsulated small interfering RNA on ovarian cancer cell growth. J Natl Cancer Inst 100: 359-372, 2008.

25. Li XY, He JL, Liu HT, Li WM and Yu C: Tetramethylpyrazine suppresses interleukin-8 expression in LPS-stimulated human umbilical vein endothelial cell by blocking ERK, p38 and nuclear factor-kappaB signaling pathways. J Ethnopharmacol 125: 83-89, 2009.

26. Inoue K, Slaton JW, Eve BY, et al: Interleukin 8 expression regulates tumorigenicity and metastases in androgen-independent prostate cancer. Clin Cancer Res 6: 2104-2119, 2000.

27. Yoshida S, Ono M, Shono T, et al: Involvement of interleukin-8, vascular endothelial growth factor, and basic fibroblast growth factor in tumor necrosis factor alpha-dependent angiogenesis. Mol Cell Biol 17: 4015-4023, 1997.

28. Bartels M, Schweda AT, Dreikhausen U, et al: Peptide-mediated disruption of NFkappaB/NRF interaction inhibits IL-8 gene activation by IL-1 or Helicobacter pylori. J Immunol 179: 7605-7613, 2007.

29. Rochelson B, Dowling O, Schwartz N and Metz CN: Magnesium sulfate suppresses inflammatory responses by human umbilical vein endothelial cells (HuVECs) through the NFkappaB pathway. J Reprod Immunol 73: 101-107, 2007.

30. Bhattacharyya S, Gutti U, Mercado J, Moore C, Pollard HB and Biswas R: MAPK signaling pathways regulate IL-8 mRNA stability and IL-8 protein expression in cystic fibrosis lung epithelial cells lines. Am J Physiol Lung Cell Mol Physiol 300: 81-87, 2011.

31. Subramaniam D, Ramalingam S, May R, et al: Gastrinmediated interleukin- 8 and cyclooxygenase- 2 gene expression: differential transcriptional and posttranscriptional mechanisms. Gastroenterology 134: 1070-1082, 2008.

32. Lee JW, Wang P, Kattah MG, et al: Differential regulation of chemokines by IL-17 in colonic epithelial cells. J Immunol 181: 6536-6545, 2008.

33. Suzuki M, Tetsuka T, Yoshida S, et al: The role of p38 mitogenactivated protein kinase in IL-6 and IL-8 production from the TNF-alpha- or IL-1beta-stimulated rheumatoid synovial fibroblasts. FEBS Lett 465: 23-27, 2000.

34. Lee WS, Yang HY, Kao PF, et al: Tetramethylpyrazine downregulates angiotensin II-induced endothelin-1 gene expression in vascular endothelial cells. Clin Exp Pharmacol Physiol 32: 845-850, 2005.

35. Liu HT, Du YG, He JL, et al: Tetramethylpyrazine inhibits production of nitric oxide and inducible nitric oxide synthase in lipopolysaccharide-induced N9 microglial cells through blockade of MAPK and PI3K/Akt signaling pathways, and suppression of intracellular reactive oxygen species. J Ethnopharmacol 129: 335-343, 2010. 
36. Karashima T, Sweeney P, Kamat A, et al: Nuclear factor- $\kappa \mathrm{B}$ mediates angiogenesis and metastasis of human bladder cancer through the regulation of interleukin-8. Clin Cancer Res 9: 2786-2797, 2003.

37. Xu L, Xie K, Mukaida N, Matsushima K and Fidler IJ: Hypoxiainduced elevation in interleukin-8 expression by human ovarian carcinoma cells. Cancer Res 59: 5822-5829, 1999.

38. $\mathrm{Xu} \mathrm{L}$ and Fidler IJ: Acidic $\mathrm{pH}$-induced elevation in interleukin 8 expression by human ovarian carcinoma cells. Cancer Res 60: 4610-4616, 2000.
39. Bi WF, Yang HY, Liu JC, et al: Inhibition of cyclic straininduced endothelin-1 secretion by tetramethylpyrazine. Clin Exp Pharmacol Physiol 32: 536-540, 2005.

40. Smeal T, Angel P, Meek J and Karin M: Different requirements for formation of Jun: Jun and Jun: Fos complexes. Genes Dev 3: 2091-2100, 1989.

41. Inoue K, Slaton JW, Kim SJ, et al: Interleukin 8 expression regulates tumorigenicity and metastasis in human bladder cancer. Cancer Res 60: 2290-2299, 2000. 